\title{
openheart Risk factors for incident heart failure with preserved or reduced ejection fraction, and valvular heart failure, in a community-based cohort
}

\author{
Fei Fei Gong, ${ }^{1,2,3}$ Michael V Jelinek, ${ }^{2,3}$ Julian M Castro, ${ }^{3}$ Jennifer M Coller, ${ }^{3}$ \\ Michele McGrady, ${ }^{4}$ Umberto Boffa, ${ }^{5}$ Louise Shiel, ${ }^{5}$ Danny Liew, ${ }^{5}$ Rory Wolfe, ${ }^{5}$ \\ Simon Stewart, ${ }^{6}$ Alice J Owen, ${ }^{5}$ Henry Krum, ${ }^{5}$ Christopher M Reid, ${ }^{5,7}$ \\ David L Prior, ${ }^{2,3}$ Duncan J Campbell ${ }^{1,2,3}$
}

\begin{abstract}
- Additional material is published online only. To view, please visit the journal online (http://dx.doi.org/10.1136/ openhrt-2018-000782)
\end{abstract}

To cite: Gong FF, Jelinek MV, Castro JM, et al. Risk factors for incident heart failure with preserved or reduced ejection fraction, and valvular heart failure, in a community-based cohort. Open Heart 2018;5:e000782. doi:10.1136/ openhrt-2018-000782

Received 16 January 2018 Revised 18 April 2018 Accepted 13 June 2018
Check for updates

(C) Author(s) (or their employer(s)) 2018. Re-use permitted under CC BY-NC. No commercial re-use. See rights and permissions. Published by BMJ.

For numbered affiliations see end of article.

Correspondence to Dr Duncan J Campbell; dcampbell@svi.edu.au

\section{ABSTRACT}

Background The lack of effective therapies for heart failure with preserved ejection fraction (HFpEF) reflects an incomplete understanding of its pathogenesis.

Design We analysed baseline risk factors for incident $\mathrm{HFpEF}$, heart failure with reduced ejection fraction (HFrEF) and valvular heart failure (VHF) in a community-based cohort.

Methods We recruited 2101 men and 1746 women $\geq 60$ years of age with hypertension, diabetes, ischaemic heart disease (IHD), abnormal heart rhythm, cerebrovascular disease or renal impairment. Exclusion criteria were known heart failure, left ventricular ejection fraction $<50 \%$ or valve abnormality >mild in severity. Median follow-up was 5.6 (IQR 4.6-6.3) years.

Results Median time to heart failure diagnosis in 162 participants was 4.5 (IQR 2.7-5.4) years, 73 with $\mathrm{HFpEF}$, 53 with HFrEF and 36 with VHF. Baseline age and aminoterminal pro-B-type natriuretic peptide levels were associated with HFpEF, HFrEF and VHF. Pulse pressure, IHD, waist circumference, obstructive sleep apnoea and pacemaker were associated with HFpEF and HFrEF; atrial fibrillation (AF) and warfarin therapy were associated with HFpEF and VHF and peripheral vascular disease and low platelet count were associated with HFrEF and VHF. Additional risk factors for HFpEF were body mass index (BMI), hypertension, diabetes, renal dysfunction, low haemoglobin, white cell count and $\beta$-blocker, statin, loop diuretic, non-steroidal anti-inflammatory and clopidogrel therapies, for HFrEF were male gender and cigarette smoking and for VHF were low diastolic blood pressure and alcohol intake. BMI, diabetes, low haemoglobin, white cell count and warfarin therapy were more strongly associated with $\mathrm{HFpEF}$ than $\mathrm{HFFEF}$, whereas male gender and low platelet count were more strongly associated with HFrEF than HFpEF

Conclusions Our data suggest a major role for BMI, hypertension, diabetes, renal dysfunction, and inflammation in HFpEF pathogenesis; strategies directed to prevention of these risk factors may prevent a sizeable proportion of $\mathrm{HFpEF}$ in the community.

Trial registration number NCT00400257, NCT00604006 and NCT01581827.

\section{Key questions}

What is already known about this subject?

- Heart failure (HF) is a heterogeneous condition that encompasses HF with preserved (HFpEF) and reduced ejection fraction (HFrEF) and valvular $\mathrm{HF}$ (VHF).

- Although there are effective therapies for HFrEF and VHF, there are no therapies that improve the prognosis of HFpEF.

- In addition, the mechanisms of HFpEF are incompletely understood.

What does this study add?

- This study reports the risk factors for HFpEF, HFrEF and VHF identified in a community-based cohort many years before diagnosis of $\mathrm{HF}$.

- Our data suggest a major role for body mass index hypertension, diabetes, renal dysfunction and inflammation in $\mathrm{HFpEF}$ pathogenesis.

How might this impact on clinical practice?

- Strategies that prevent increased body mass index hypertension, diabetes, renal dysfunction and inflammation may prevent HFpEF.

\section{INTRODUCTION}

Heart failure (HF) is a major cause of premature morbidity and mortality with a lifetime risk of $20 \%-46 \%,{ }^{1}$ and preventive strategies focused on pathogenic mechanisms are required. It is a complex clinical syndrome that results from any structural or functional impairment of ventricular filling or ejection of blood that may result from disorders of the pericardium, myocardium, endocardium, heart valves, great vessels or metabolic abnormalities, but most patients with HF have symptoms due to impaired left ventricular (LV) structure or function. ${ }^{2}$ Apart from HF due primarily to valvular dysfunction (valvular $\mathrm{HF}$ (VHF)), which can often be corrected by valve 
surgery, HF is usually categorised according to the LV ejection fraction (LVEF), with $\mathrm{HF}$ with $\mathrm{LVEF} \geq 50 \%$ referred to as $\mathrm{HF}$ with preserved ejection fraction (HFpEF) and $\mathrm{HF}$ with LVEF $<50 \%$ referred to as HF with reduced ejection fraction (HFrEF). ${ }^{3}$ Separation of non-valvular HF into HFpEF and HFrEF is important because although there are many therapies that improve the prognosis of HFrEF, there are as yet no therapies that improve the prognosis of HFpEF. ${ }^{4}$ More recently, HFrEF has been subdivided into mid-range (LVEF 40\%-49\%) and reduced ejection fraction (LVEF $<40 \%$ ) because the therapeutic improvement in prognosis of patients with HFrEF was demonstrated in those with LVEF $<35 \% .{ }^{4} \mathrm{HFpEF}$ accounts for approximately half of HF in the community, ${ }^{5}$ and the lack of therapies that improve the prognosis of this condition reflects an incomplete understanding of its pathogenesis.

Only limited information is available concerning the risk factors for incident HFpEF and HFrEF. ${ }^{6-10}$ Moreover, previous studies of HF incidence have either not mentioned valvular disease, ${ }^{69}$ or included VHF within the HFrEF and HFpEF classifications. ${ }^{7811}$ To gain insight into the different pathogenic mechanisms of HFpEF, HFrEF and VHF, we analysed risk factors for incident HF in participants of the SCReening Evaluation of the Evolution of New HF (SCREEN-HF) study, a prospective cohort study of men and women recruited from the community $\geq 60$ years of age without HF, but with risk factors for HF. We hypothesised that the risk factor profiles of HFpEF, HFrEF and VHF may suggest distinct pathophysiological mechanisms.

\section{METHODS}

\section{Study population}

The SCREEN-HF study was a community-based evaluation of the use of serum amino-terminal pro-B-type natriuretic peptide (NT-proBNP) to identify individuals with cardiac dysfunction (as assessed by echocardiography) and increased risk of $\mathrm{HF}$ and other cardiovascular events, which has been described elsewhere. ${ }^{12}$ We report here the follow-up of the SCREEN-HF cohort to detect incident HF. The flow chart for participant recruitment and follow-up is shown in figure 1. In summary, 44000 members of private health fund Bupa, resident in Melbourne or Shepparton, Victoria, Australia, were invited to participate. Inclusion criteria were age $\geq 60$ years with one or more of self-reported treatment for hypertension or diabetes for $\geq 2$ years, myocardial infarction (MI) or other ischaemic heart disease (IHD) or valvular heart disease, irregular or rapid heart rhythm, cerebrovascular disease or renal impairment. Exclusion criteria were previously diagnosed $\mathrm{HF}$, previous valve surgery or documented valve abnormality graded $>$ mild or LVEF $<50 \%$ on previous echocardiography or other cardiac imaging. Documentation of previous cardiac imaging was requested from hospitals and from the participant's primary care provider, physician and cardiologist. However, for this community-based cohort, most participants had not had cardiac imaging before enrolment. Recruitment commenced in May 2007 and was completed in January 2010.

Of the 4054 individuals enrolled at the baseline visit (visit 1), 3847 met the inclusion and exclusion criteria, of which $92 \%$ were Bupa members. The baseline visit was conducted by a study research nurse who consented, interviewed and examined the participant and collected a non-fasting blood sample for measurement of electrolytes, creatinine, urea, glucose, full blood examination and NT-proBNP. Details of symptoms, interim clinical events and medication were collected, echocardiography was performed and the participant examined for signs of HF during visits 2 and 3. Additionally, details of interim clinical events, symptoms and medication were collected by telephone interview approximately 4 and 7 years following enrolment. Follow-up was completed between 2013 and 2015. The SCREEN-HF study was approved by the Alfred Human Research Ethics Committee and written informed consent was obtained from all participants. The study was registered at ClinicalTrials.gov NCT00400257, NCT00604006 and NCT01581827.

\section{Study variables}

Baseline clinical factors

Age, sex and past medical history, which included IHD (MI, angina, coronary revascularisation), valvular or other heart disease or heart surgery, hypertension, respiratory disease, renal impairment, cardiac arrhythmia including atrial fibrillation (AF), cerebrovascular disease, diabetes, peripheral vascular disease (PVD, including aortic and carotid disease), obstructive sleep apnoea (OSA) and pacemaker use, based on self-report, were recorded. Of the 3294 participants with hypertension at enrolment, $99 \%$ were receiving antihypertensive therapy. Of the 703 participants with diabetes at enrolment, $74 \%$ were receiving oral antidiabetic and/or insulin therapy and the remainder were treated with diet alone. Self-reported details of lifestyle factors included smoking history and alcohol intake. Height, weight and waist circumference were measured, and blood pressure (BP) and heart rate were measured with an automatic BP monitor (A\&D Medical, Kensington, Victoria) after sitting for at least $5 \mathrm{~min}$. Two BP readings were taken $3 \mathrm{~min}$ apart and the present analysis uses the mean of these two readings. Participants brought details of their medications to the baseline study visit, which were recorded.

Body mass index (BMI) was calculated as the ratio of weight to height squared $\left(\mathrm{kg} / \mathrm{m}^{2}\right)$. Estimated glomerular filtration rate (eGFR) was calculated using the Modification of Diet in Renal Disease study equation. ${ }^{13}$ Serum NT-proBNP was measured by electrochemiluminescence immunoassay using an Elecsys instrument (Roche Diagnostics, Basel, Switzerland) with a lower limit of detection of $0.6 \mathrm{pmol} / \mathrm{L}$. 


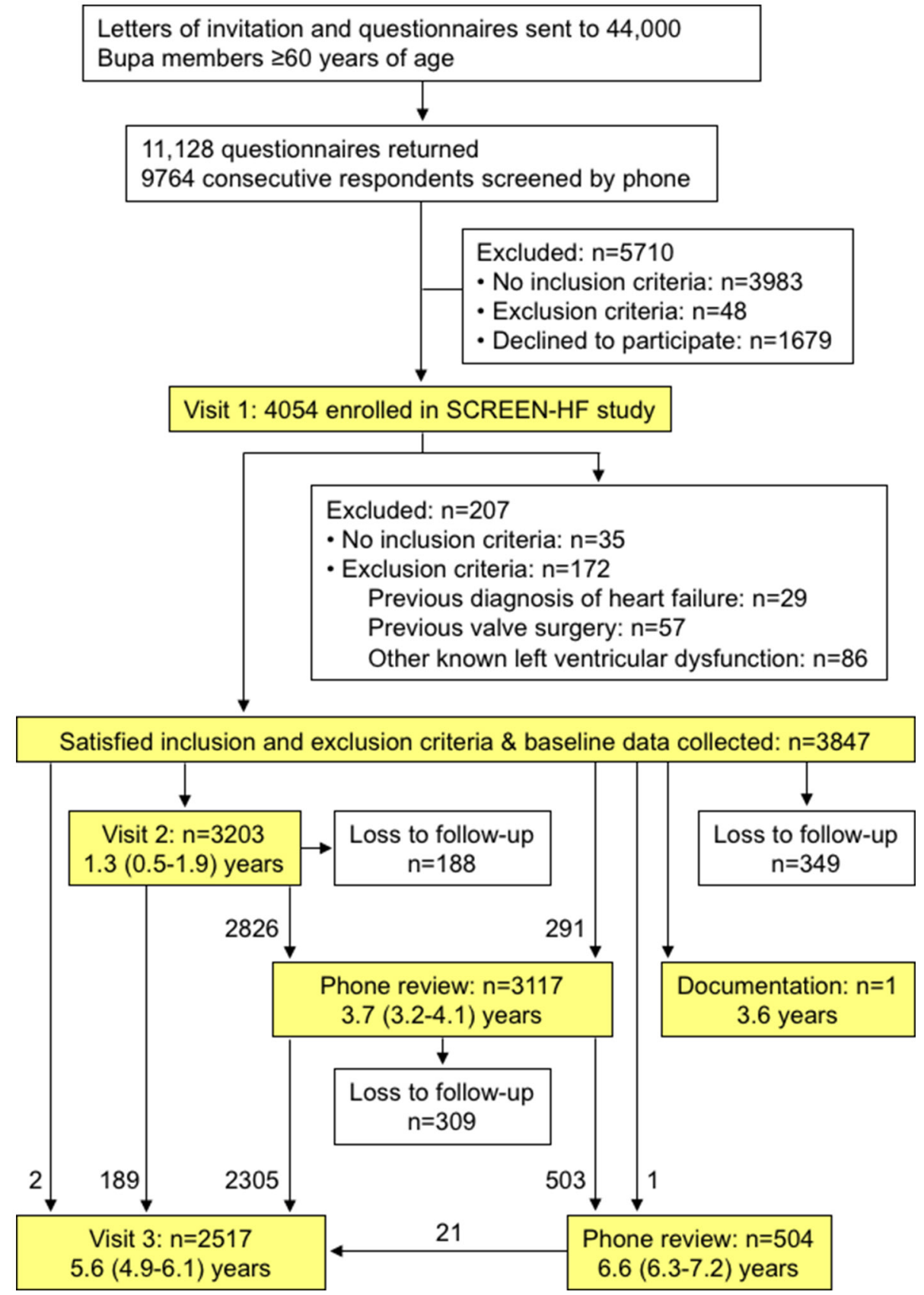

Figure 1 Consolidated Standards of Reporting Trials flow diagram describing participant recruitment and follow-up in the SCReening Evaluation of the Evolution of New HF (SCREEN-HF) study. Durations of follow-up for visits and phone review are shown as medians (IQR).

\section{HF and other events}

In order to capture all incident cases of HF, a participant was referred to their cardiologist or to a SCREEN-HF study cardiologist if they reported symptoms consistent with HF or if signs consistent with HF were detected during a study visit, and information was requested from the participant's primary care provider, physician and cardiologist. All participant files were reviewed by a cardiovascular physician and documentation of all deaths and other events was requested from hospitals and the participant's primary care provider, physician and cardiologist. All diagnoses of $\mathrm{HF}$ and suspicion of
HF were submitted to adjudication by two HF specialists according to European Society of Cardiology (ESC) criteria of 2012. ${ }^{3}$ The adjudicators were provided with all available information including reports of imaging studies; however, they were not informed of the baseline NT-proBNP level, although they were informed of any NT-proBNP and BNP levels measured as part of usual care. When one adjudicator made a diagnosis of HF and the other did not, a third HF specialist adjudicated on the presence or absence of HF. Based on cardiac imaging at the time of or after HF diagnosis, non-valvular $\mathrm{HF}$ was categorised as either HFpEF 
(LVEF $\geq 50 \%$ ) or HFrEF (LVEF $<50 \%$ ), and VHF was diagnosed when HF was attributed to valvular dysfunction graded as severe.

\section{Statistical analysis}

Continuous variables were summarised as means (SD) or medians (IQR), depending on their distribution exhibiting skewness. Categorical variables were summarised as numbers (percentages). Comparisons between participant groups were performed with the use of Student's t-test for continuous variables that were approximately normally distributed with or without log transformation, or with the use of Mann-Whitney U test. Categorical variables were compared with the use of $\mathrm{X}^{2}$ test or Fisher's exact test.

Data were complete for the 162 participants who developed HF, except for one with missing BP and heart rate. Of 3685 participants who did not develop HF during follow-up, the maximum number with missing data was 13 for platelet count. In multivariable analysis, the maximum number with missing data was 21. Participants were omitted from particular analyses if the required variables were missing.

Except for the analysis of survival after HF diagnosis, data were censored at the date of last contact or development of HF or death, whichever came first. Incidence rate data were analysed using Poisson regression. Survival after diagnosis of HFpEF, HFrEF or VHF was compared using Kaplan-Meier curves and a log-rank test. Cumulative incidence curves were constructed with the use of the non-parametric cumulative incidence function of Fine and Gray, ${ }^{14}$ with non-HF-related death and other categories of $\mathrm{HF}$ as competing risks. HRs for univariate risk factors for $\mathrm{HF}$ outcomes were calculated using a semiparametric proportional hazards model for the subdistribution of competing risk, with non-HF-related death and other categories of $\mathrm{HF}$ as competing risks. ${ }^{14}$ Martingale residuals were calculated to test for non-linearity of continuous variables, and Schoenfeld residuals were calculated to assess whether proportional hazards assumptions were satisfied. Although log NT-proBNP levels were normally distributed, Martingale residuals revealed non-linearity for the association of $\log$ NT-proBNP with log-hazard, and therefore NT-proBNP levels were divided into quintiles for the calculation of HRs. Multivariable models were constructed by backward selection using Akaike information criteria and competing models compared using Bayesian information criteria. The HR associating each risk factor with HFpEF versus HFrEF were formally tested for equality using the method of Lunn and McNeil. ${ }^{15} \mathrm{C}$ statistics were estimated from time-dependent areas under receiver operating characteristic curves for censored event times with competing risks. ${ }^{16} \mathrm{~A}$ two-sided $\mathrm{p}$ value of $<0.05$ was considered to indicate statistical significance. Data were analysed with SPSS software V.22 and with R software V.1.0.153.

\section{RESULTS}

\section{HF diagnosis}

The median follow-up of the 3847 participants was 5.6 (IQR 4.6-6.3) years, with 271 non-HF-related deaths during follow-up. Files from 193 participants were submitted to adjudication, with $77 \%$ agreement between the two adjudicators with respect to the presence or absence of HF according to ESC criteria of $2012^{3} ; 45$ cases for which one adjudicator diagnosed HF and one adjudicator was equivocal were submitted to adjudication by a third HF specialist. Of the 162 participants with a HF diagnosis confirmed by two HF specialists, 63 were diagnosed on hospitalisation. Excluding hospitalisations for valve surgery, a further 44 participants were hospitalised for HF after HF diagnosis. Of the 99 participants diagnosed with HF in the ambulant setting, 76 were initially diagnosed by their cardiologist or primary care provider and 23 were initially diagnosed by SCREEN-HF investigators. When age on enrolment was categorised according to $<70,70-79$ and $\geq 80$ years, there were significant differences in HF incidence rate between the three age groups, but no difference between men and women (see online supplementary figure 1 ).

All HF cases had cardiac imaging either at the time of HF diagnosis or after HF diagnosis; 121 within 30 days of HF diagnosis and the remaining 41 were imaged a median of 177 (IQR 64-340) days post-HF diagnosis; however, all but four participants imaged $>30$ days post-HF diagnosis had echocardiography before HF diagnosis. The predominant modality for LVEF determination at the time of HF diagnosis or after HF diagnosis was echocardiography $(\mathrm{n}=150)$, but also included left ventriculogram $(n=10)$ and myocardial perfusion scan $(n=2)$. Of the 162 HF cases, 73 were HFpEF, 53 were HFrEF and 36 were VHF. We did not subclassify participants with HFrEF as mid-range (LVEF $40 \%-49 \%$ ) or more severe HFrEF (LVEF $<40 \%$ ) because LVEF assessment was only qualitative for 16 of the 53 participants who developed HFrEF; of 37 reports with quantitative LVEF assessment, 28 (76 $\%$ ) reported LVEF $<40 \%$.

The cumulative incidences of total HF, HFpEF, HFrEF and VHF are shown in figure 2. The median time to HF diagnosis was 4.5 (IQR 2.7-5.4) years for all 162 participants with HF, 4.5 (2.9-5.5) years for participants who developed HFpEF, 4.8 (2.3-5.4) years for those who developed HFrEF and 4.2 (2.9-5.2) years for those who developed VHF.

The 36 participants who developed VHF included 1 with aortic regurgitation, 22 with aortic stenosis and 13 with mitral regurgitation that included 3 with acute onset due to endocarditis of the mitral valve $(n=1)$ or chordal rupture $(n=2)$. Of the 36 participants who developed VHF, 31 had subsequent valve surgery. One participant with HFrEF had valve surgery at the time of coronary artery bypass graft surgery. Mortality following HF diagnosis was similar for HFpEF, HFrEF and VHF (see online supplementary figure 2 ). 


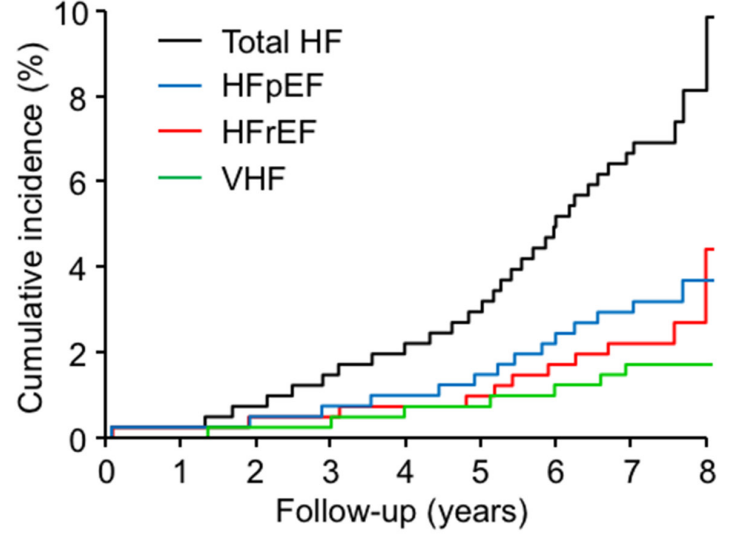

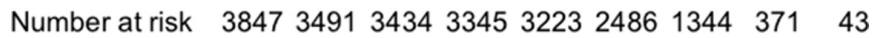

Figure 2 Cumulative incidence of total heart failure (total $\mathrm{HF})$, heart failure with preserved (HFpEF) and reduced ejection fraction (HFrEF) and valvular heart failure (VHF). Cumulative incidence curves were constructed with the use of the non-parametric cumulative incidence function of Fine and Gray, with non-HF-related death and other categories of HF as competing risks. ${ }^{14}$

\section{Baseline clinical variables}

Baseline data for participants who developed HF during follow-up, and those who did not, are shown in table 1 . In comparison with participants who did not develop HF during follow-up, participants who developed HF were older, with higher pulse pressure (PP), lower diastolic BP (DBP), lower heart rate and higher BMI and waist circumference, and a higher prevalence of diabetes, prior $\mathrm{MI}$ and coronary revascularisation, $\mathrm{PVD}, \mathrm{AF}$, pacemaker, OSA and smoking. Participants who developed HF also had higher NT-proBNP levels, lower eGFR, lower haemoglobin, higher white cell count (WCC) and lower platelet count, and were more likely to be taking $\beta$-blocker, ACE inhibitor, statin, loop diuretic, non-steroidal anti-inflammatory drug (NSAID), clopidogrel and warfarin therapies.

There were also differences in baseline variables between participants who developed HFpEF, HFrEF or VHF (table 2). In comparison with participants who developed HFrEF during follow-up, participants who developed HFpEF were more likely to be female, have higher $\mathrm{BMI}$, be diabetic, have $\mathrm{AF}$ and to have lower haemoglobin, higher WCC and higher platelet count.

\section{Risk factors for incident HFpEF, HFrEF and VHF}

Baseline variables with statistically significant association with incident HFpEF, HFrEF or VHF in univariate analysis are shown in figure 3, and univariate HRs for the association of total HF, HFpEF, HFrEF and VHF with all baseline variables are shown in the online supplementary table 1. Age and NT-proBNP levels were associated with HFpEF, HFrEF and VHF. PP, IHD, waist circumference, OSA and pacemaker were associated with HFpEF and HFrEF; AF and warfarin therapy were associated with $\mathrm{HFpEF}$ and VHF and PVD and low platelet count were associated with HFrEF and VHF. Additional risk factors for HFpEF were
BMI, diabetes, low eGFR, low haemoglobin, WCC and $\beta$-blocker, statin, loop diuretic, NSAID and clopidogrel therapies, for HFrEF were male gender and cigarette smoking, and for VHF were low DBP and alcohol intake. When HR were compared between HFpEF and HFrEF, BMI $(p=0.003)$, diabetes $(p=0.009), A F(p=0.009)$, low haemoglobin $(\mathrm{p}=0.001)$, WCC $(\mathrm{p}=0.002)$ and warfarin therapy $(p=0.025)$ were more strongly associated with HFpEF than HFrEF, whereas male gender $(p<0.0001)$ and low platelet count $(\mathrm{p}=0.004)$ were more strongly associated with HFrEF than HFpEF.

Although not associated with incident HFpEF in univariate analysis, hypertension was associated with increased HR and calcium channel blocker therapy was associated reduced HR for incident HFpEF in multivariable analysis, together with age, NT-proBNP, BMI, diabetes, MI, $\mathrm{AF}$ and low haemoglobin (table 3). In addition to age and NT-proBNP, male gender, waist circumference and MI were associated with incident HFrEF in multivariable analysis. NT-proBNP, low DBP and alcohol intake were associated with incident VHF in multivariable analysis.

Many variables associated with incident $\mathrm{HF}$ in univariate analyses, including $\mathrm{AF}$, and loop diuretic and $\beta$-blocker therapies were associated with increased NT-proBNP levels, whereas other variables associated with incident $\mathrm{HF}$, such as male gender, diabetes, BMI, waist circumference and increased alcohol intake were associated with lower NT-proBNP levels (online supplementary table 2 and 3 ).

There were several instances of non-proportional hazards due to statistically significant $(\mathrm{p}<0.0001)$ interactions between risk factors and duration of follow-up, thereby indicating that the HR for the risk factor varied according to the duration of follow-up. In exploratory analyses, when follow-up was split into two periods, proportional hazards existed within each period (online supplementary table 4 ).

\section{DISCUSSION}

We found a wide range of risk factors for incident $\mathrm{HFpEF}$, HFrEF and VHF in the SCREEN-HF cohort. To obtain information about the early stages of HF pathogenesis, we excluded individuals with known LVEF $<50 \%$, previous valve surgery or documented valve abnormality graded >mild on enrolment, and the median time to HF diagnosis was 4-5 years after enrolment. Moreover, the majority of HF diagnoses and LVEF assessments in the SCREEN-HF study were made in the ambulant setting, in contrast to previous studies where HF diagnosis or LVEF assessment was based on hospitalisation. ${ }^{6-9}$ The association of incident HFpEF, HFrEF and VHF with increased baseline levels of NT-proBNP, a marker of cardiomyocyte stretch predominantly released from the ventricles, ${ }^{17}$ suggests that the mechanisms of HF pathogenesis were in play at the time of enrolment many years before HF diagnosis. Thus, the risk factors for HF identified in the SCREEN-HF cohort may suggest mechanisms of HF 
Table 1 Baseline characteristics of subjects who developed new-onset heart failure and of subjects without heart failure during follow-up

\begin{tabular}{|c|c|c|c|}
\hline & $\mathrm{HF}(n, \%) n=162$ & No HF $(n, \%) n=3685$ & $P$ values \\
\hline Age at enrolment (years) & $75(70,79)$ & $69(65,75)$ & $<0.0001$ \\
\hline Male & $98(60 \%)$ & $2003(54 \%)$ & 0.13 \\
\hline $\mathrm{SBP}(\mathrm{mm} \mathrm{Hg})$ & $143 \pm 19$ & $141 \pm 18$ & 0.06 \\
\hline $\mathrm{DBP}(\mathrm{mm} \mathrm{Hg})$ & $79 \pm 11$ & $81 \pm 10$ & 0.019 \\
\hline $\mathrm{PP}(\mathrm{mm} \mathrm{Hg})$ & $65 \pm 16$ & $60 \pm 15$ & $<0.0001$ \\
\hline Heart rate (bpm) & $68(61,76)$ & $70(63,79)$ & 0.013 \\
\hline $\operatorname{BMl}\left(\mathrm{kg} / \mathrm{m}^{2}\right)$ & $29(26,32)$ & $28(25,31)$ & $<0.0001$ \\
\hline Waist circumference (cm) & $104 \pm 13$ & $100 \pm 19$ & 0.0035 \\
\hline Hypertension & $145(90 \%)$ & $3149(85 \%)$ & 0.17 \\
\hline Diabetes & $44(27 \%)$ & $659(18 \%)$ & 0.0048 \\
\hline Myocardial infarction & $37(23 \%)$ & $354(10 \%)$ & $<0.0001$ \\
\hline Coronary revascularisation & $42(26 \%)$ & $534(14 \%)$ & 0.0002 \\
\hline Stroke/TIA & $21(13 \%)$ & $400(11 \%)$ & 0.37 \\
\hline PVD & $15(9 \%)$ & $110(3 \%)$ & 0.0002 \\
\hline AF & $37(23 \%)$ & $356(10 \%)$ & $<0.0001$ \\
\hline Pacemaker & $7(4.3 \%)$ & $59(1.6 \%)$ & 0.020 \\
\hline OSA & $21(13 \%)$ & $258(7 \%)$ & 0.0078 \\
\hline Smoker (current or former) & $93(57 \%)$ & $1796(49 \%)$ & 0.037 \\
\hline Alcohol>2 drinks/day* & $39(24 \%)$ & $723(20 \%)$ & 0.19 \\
\hline \multicolumn{4}{|c|}{ Biochemistry and haematology } \\
\hline NT-proBNP (pmol/L) & $36(20,75)$ & $12(6,22)$ & $<0.0001$ \\
\hline eGFR $\left(\mathrm{mL} / \mathrm{min} / 1.73 \mathrm{~m}^{2}\right)$ & $67 \pm 18$ & $73 \pm 17$ & $<0.0001$ \\
\hline Haemoglobin (g/dL) & $13.7 \pm 1.6$ & $14.0 \pm 1.3$ & 0.013 \\
\hline WCC $\left(x 10^{9} / \mathrm{L}\right)$ & $7.6(6.3,8.6)$ & $7.1(6.1,8.2)$ & 0.030 \\
\hline Platelets $\left(x 10^{9} / \mathrm{L}\right)$ & $218(180,253)$ & $229(195,267)$ & 0.013 \\
\hline \multicolumn{4}{|l|}{ Medication } \\
\hline$\beta$-Blocker & $61(38 \%)$ & $828(22 \%)$ & $<0.0001$ \\
\hline ACE inhibitor & $62(38 \%)$ & $1125(31 \%)$ & 0.045 \\
\hline ARB & $70(43 \%)$ & $1735(47 \%)$ & 0.34 \\
\hline ACE inhibitor or ARB & $124(77 \%)$ & $2726(74 \%)$ & 0.52 \\
\hline CCB & $51(31 \%)$ & $998(27 \%)$ & 0.24 \\
\hline Statin & $97(60 \%)$ & $1896(51 \%)$ & 0.037 \\
\hline Thiazide diuretic & $48(30 \%)$ & $1134(31 \%)$ & 0.79 \\
\hline Loop diuretic & $19(11.7 \%)$ & $90(2.4 \%)$ & $<0.0001$ \\
\hline Aspirin & $73(45 \%)$ & $1530(42 \%)$ & 0.37 \\
\hline NSAID & $23(14.2 \%)$ & 301 (8.2\%) & 0.013 \\
\hline Clopidogrel & $19(11.7 \%)$ & $221(6.0 \%)$ & 0.0069 \\
\hline Warfarin & $20(12.3 \%)$ & $158(4.3 \%)$ & $<0.0001$ \\
\hline
\end{tabular}

Data shown as mean \pm SD, median (IQR) or $\mathrm{n}(\%)$.

${ }^{*}$ Refers to consumption of more than two standard drinks on any day.

$\mathrm{AF}$, atrial fibrillation; ARB, angiotensin II type 1 receptor blocker; BMI, body mass index; CCB, calcium channel blocker; DBP, diastolic blood pressure; eGFR, estimated glomerular filtration rate; HF, heart failure; HFpEF, heart failure with preserved ejection fraction; HFrEF, heart failure with reduced ejection fraction; NT-proBNP, amino-terminal pro-B-type natriuretic peptide; NSAID, non-steroidal anti-inflammatory drug; OSA, obstructive sleep apnoea; PP, pulse pressure; PVD, peripheral vascular disease; SBP, systolic blood pressure; TIA, transient ischaemic attack; VHF, valvular heart failure; WCC, white cell count. 
Table 2 Baseline characteristics of subjects who developed HFpEF, HFrEF or VHF during follow-up

\begin{tabular}{|c|c|c|c|c|c|c|}
\hline & HFpEF $n=73$ & HFrEF $n=53$ & VHF $n=36$ & $\begin{array}{l}\text { P values HFpEF } \\
\text { vs HFrEF }\end{array}$ & $\begin{array}{l}\text { P values HFpEF } \\
\text { vs VHF }\end{array}$ & $\begin{array}{l}\text { P values HFrEF } \\
\text { vs VHF }\end{array}$ \\
\hline Age at enrolment (years) & $76(71-79)$ & $74(71-79)$ & $72(68-79)$ & 0.52 & 0.11 & 0.26 \\
\hline Male & $33(45 \%)$ & $43(81 \%)$ & $22(61 \%)$ & $<0.0001$ & 0.15 & 0.052 \\
\hline $\mathrm{SBP}(\mathrm{mm} \mathrm{Hg})$ & $144 \pm 19$ & $145 \pm 19$ & $141 \pm 17$ & 0.84 & 0.42 & 0.34 \\
\hline $\mathrm{DBP}(\mathrm{mm} \mathrm{Hg})$ & $80 \pm 10$ & $80 \pm 13$ & $76 \pm 10$ & 0.96 & 0.08 & 0.14 \\
\hline PP (mm Hg) & $64 \pm 16$ & $65 \pm 15$ & $65 \pm 17$ & 0.81 & 0.87 & 0.96 \\
\hline Heart rate (bpm) & $68(62,75)$ & $69(61,79)$ & $67(60,79)$ & 0.70 & 0.82 & 0.63 \\
\hline BMI $\left(\mathrm{kg} / \mathrm{m}^{2}\right)$ & $31(28,35)$ & $29(26,31)$ & $28(24,31)$ & 0.005 & $<0.0001$ & 0.10 \\
\hline Waist circumference (cm) & $107 \pm 12$ & $104 \pm 14$ & $98 \pm 12$ & 0.30 & 0.0007 & 0.029 \\
\hline Hypertension & $68(93 \%)$ & $47(89 \%)$ & $30(83 \%)$ & 0.52 & 0.17 & 0.54 \\
\hline Diabetes & $30(41 \%)$ & $10(19 \%)$ & $4(11 \%)$ & 0.011 & 0.0018 & 0.39 \\
\hline Myocardial infarction & $19(26 \%)$ & $16(30 \%)$ & $2(6 \%)$ & 0.69 & 0.010 & 0.006 \\
\hline $\begin{array}{l}\text { Coronary } \\
\text { revascularisation }\end{array}$ & $20(27 \%)$ & $16(30 \%)$ & $6(17 \%)$ & 0.84 & 0.24 & 0.21 \\
\hline Stroke/TIA & $13(18 \%)$ & $5(9 \%)$ & $3(8 \%)$ & 0.21 & 0.25 & 1.00 \\
\hline PVD & $4(5 \%)$ & $7(13 \%)$ & $4(11 \%)$ & 0.20 & 0.44 & 1.0 \\
\hline AF & $23(32 \%)$ & $6(11 \%)$ & $8(22 \%)$ & 0.0097 & 0.37 & 0.24 \\
\hline Pacemaker & $4(5 \%)$ & $3(6 \%)$ & $0(0 \%)$ & 1.0 & 0.30 & 0.27 \\
\hline OSA & $11(15 \%)$ & $8(15 \%)$ & $2(6 \%)$ & 1.00 & 0.21 & 0.19 \\
\hline Smoker (current or former) & $38(52 \%)$ & $34(64 \%)$ & $21(58 \%)$ & 0.20 & 0.55 & 0.66 \\
\hline Alcohol $>2$ drinks/day* & $11(15 \%)$ & $15(28 \%)$ & $13(36 \%)$ & 0.079 & 0.025 & 0.49 \\
\hline \multicolumn{7}{|l|}{$\begin{array}{l}\text { Biochemistry and } \\
\text { haematology }\end{array}$} \\
\hline NT-proBNP (pmol/L) & $37(23,70)$ & $38(20,80)$ & $32(14,72)$ & 0.62 & 0.25 & 0.47 \\
\hline eGFR $\left(\mathrm{mL} / \mathrm{min} / 1.73 \mathrm{~m}^{2}\right)$ & $65 \pm 17$ & $68 \pm 18$ & $69 \pm 19$ & 0.34 & 0.27 & 0.82 \\
\hline Haemoglobin $(\mathrm{g} / \mathrm{dL})$ & $13.3 \pm 1.5$ & $14.2 \pm 1.6$ & $13.8 \pm 1.5$ & 0.0015 & 0.12 & 0.20 \\
\hline WCC $\left(x 10^{9} / L\right)$ & $8.2(6.7,9.2)$ & $7.1(6.1,7.9)$ & $7.3(5.8,8.3)$ & 0.0057 & 0.019 & 0.86 \\
\hline Platelets $\left(x 10^{9} / \mathrm{L}\right)$ & $233(188,277)$ & $210(179,235)$ & $204(171,236)$ & 0.0070 & 0.063 & 0.58 \\
\hline \multicolumn{7}{|l|}{ Medication } \\
\hline$\beta$-Blocker & $34(47 \%)$ & $16(30 \%)$ & $11(31 \%)$ & 0.069 & 0.15 & 1.0 \\
\hline ACE inhibitor & $24(33 \%)$ & $22(42 \%)$ & $16(44 \%)$ & 0.35 & 0.29 & 0.83 \\
\hline ARB & 39 (53\%) & $19(36 \%)$ & $12(33 \%)$ & 0.070 & 0.066 & 0.83 \\
\hline ACE inhibitor or ARB & 58 (79\%) & $40(75 \%)$ & $26(72 \%)$ & 0.67 & 0.47 & 0.81 \\
\hline СCB & $19(26 \%)$ & $21(40 \%)$ & $11(31 \%)$ & 0.12 & 0.65 & 0.50 \\
\hline Statin & $48(66 \%)$ & $30(57 \%)$ & $19(53 \%)$ & 0.35 & 0.21 & 0.83 \\
\hline Thiazide diuretic & $27(37 \%)$ & $12(23 \%)$ & $9(25 \%)$ & 0.12 & 0.28 & 0.80 \\
\hline Loop diuretic & $13(17.8 \%)$ & $4(7.5 \%)$ & $2(5.6 \%)$ & 0.12 & 0.14 & 1.0 \\
\hline Aspirin & $30(41 \%)$ & $28(53 \%)$ & $15(42 \%)$ & 0.21 & 1.0 & 0.39 \\
\hline NSAID & $11(15 \%)$ & $8(15 \%)$ & $4(11 \%)$ & 1.0 & 0.77 & 0.76 \\
\hline Clopidogrel & $10(13.7 \%)$ & $7(13.2 \%)$ & $2(5.6 \%)$ & 1.0 & 0.33 & 0.30 \\
\hline Warfarin & $13(17.8 \%)$ & $2(3.8 \%)$ & $5(13.9 \%)$ & 0.024 & 0.79 & 0.11 \\
\hline
\end{tabular}

Data shown as mean $\pm \mathrm{SD}$, median (IQR) or $\mathrm{n}(\%)$.

*Refers to consumption of more than two standard drinks on any day.

$\mathrm{AF}$, atrial fibrillation; ARB, angiotensin II type 1 receptor blocker; BMI, body mass index; CCB, calcium channel blocker; DBP, diastolic blood pressure; eGFR, estimated glomerular filtration rate; $\mathrm{HFpEF}$, heart failure with preserved ejection fraction; $\mathrm{HFrEF}$, heart failure with reduced ejection fraction; NT-proBNP, amino-terminal pro-B-type natriuretic peptide; NSAID, non-steroidal antiinflammatory drug; OSA, obstructive sleep apnoea; PP, pulse pressure; PVD, peripheral vascular disease; SBP, systolic blood pressure; TIA, transient ischaemic attack; VHF, valvular heart failure; WCC, white cell count. 


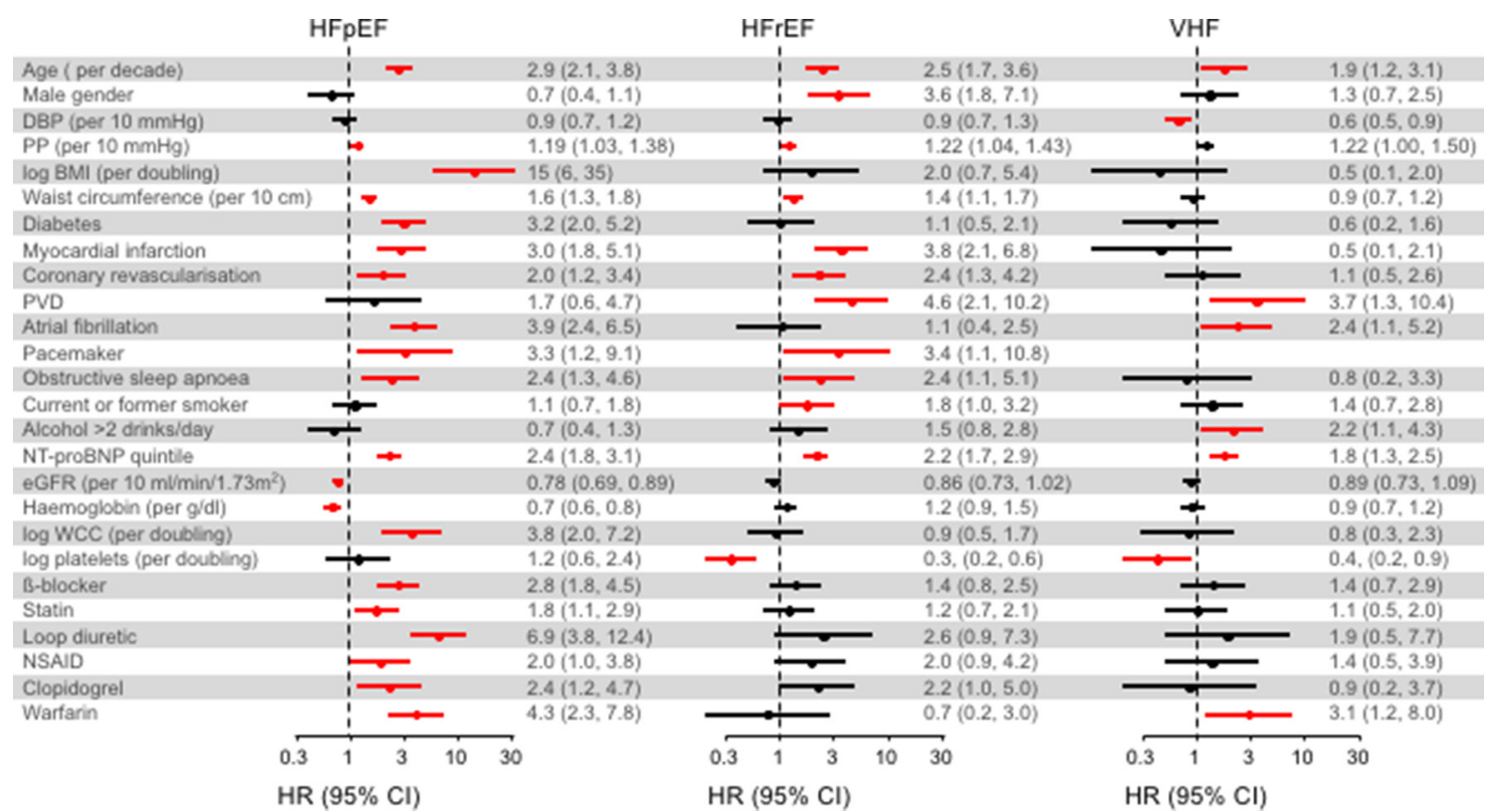

Figure 3 Forest plots showing univariate HRs and 95\% Cls for risk factors for incident heart failure (HF) with preserved (HFpEF) and reduced ejection fraction (HFrEF) and valvular HF (VHF), where a risk factor was significantly associated with at least one category of HF; HRs significantly different from $1(p<0.05)$ are shown in red. HRs for all risk factors for total HF, HFpEF, HFrEF and VHF are shown in the online supplementary table 1. BMI, body mass index; DBP, diastolic blood pressure; eGFR, estimated glomerular filtration rate; NT-proBNP, amino-terminal pro-B-type natriuretic peptide; NSAID, non-steroidal anti-inflammatory drug; PP, pulse pressure; PVD, peripheral vascular disease; WCC, white cell count. Alcohol>2 drinks/day refers to consumption of more than two standard drinks on any day. HRs were calculated using a semiparametric proportional hazards model for the subdistribution of competing risk, with non-HF-related death and other categories of HF as competing risks. ${ }^{14}$

pathogenesis and potential strategies for its prevention and treatment.

Age, male gender, coronary disease, hypertension, PP, diabetes, AF, smoking, BMI, valvular heart disease, LV hypertrophy and black race are established risk factors for incident $\mathrm{HF}$ as a broad clinical syndrome. ${ }^{18} 19$ Moreover, previously reported risk factors for valvular dysfunction include rheumatic heart disease, age, gender, tobacco use, hypercholesterolaemia, hypertension, type 2 diabetes, MI, cardiomyopathies, inflammatory diseases, drugs and radiation. ${ }^{20}{ }^{21} \mathrm{Few}$ studies have examined the risk factors for incident HFpEF and HFrEF separately. ${ }^{6-10}$ A pooled analysis of HFpEF ( $\mathrm{LVEF}>45 \%$ ) and $\mathrm{HFrEF}$ (LVEF $\leq 45 \%$ ) cohorts found that age, SBP, BMI, antihypertensive treatment, diabetes, alcohol use and previous MI were risk factors for HFpEF; the same risk factors were associated with HFrEF, in addition to male gender, DBP, heart rate, smoking, previous stroke, left ventricular hypertrophy and left bundle branch block. ${ }^{10}$ In addition, Brouwers et al reported NT-proBNP level was a risk factor for both HFpEF (LVEF $\geq 50 \%$ ) and HFrEF (LVEF $\leq 40 \%$ ) in multivariable analysis; cystatin $\mathrm{C}$ level was a risk factor for HFpEF, and troponin level was a risk factor for HFrEF, whereas $\mathrm{AF}$ was associated with reduced HFrEF risk. ${ }^{9}$

In contrast to previous studies of risk factors for incident HFpEF and HFrEF that either did not mention valvular disease, ${ }^{69}$ or included VHF within the HFpEF and HFrEF categories, ${ }^{7811}$ we separated VHF from HFpEF and HFrEF. In addition, we provide information about waist circumference, coronary revascularisation, PVD, AF, pacemaker, OSA, eGFR, haemoglobin, WCC, platelet count and cardiovascular therapies as risk factors for HFpEF, HFrEF and VHF. The association of age, male gender, IHD, NT-proBNP and smoking with incident HFrEF in the SCREEN-HF cohort was in agreement with previous studies. ${ }^{8-10}$ Risk factors common to HFrEF and HFpEF were age, NT-proBNP, IHD, PP, waist circumference, OSA and pacemaker. Increased PP is a marker of increased arterial stiffness that may, through altered ventriculo-arterial coupling, simultaneously increase systolic load and reduce DBP, thereby compromising both cardiac output and myocardial perfusion. ${ }^{22}$ Waist circumference, but not BMI, was a risk factor for HFrEF; this association was retained in multivariable analysis after adjusting for gender, and central obesity may have contributed to the pathogenesis of HFrEF, and to OSA. The mechanism of the association between lower baseline platelet count and incident HFrEF and VHF is unknown and may reflect increased platelet consumption. The association of $\mathrm{AF}$ and warfarin therapy with incident HFpEF and VHF may indicate a role for atrial arrhythmias in HF pathogenesis. However, given the higher NT-proBNP levels in participants with $\mathrm{AF}$, it is also possible that $\mathrm{AF}$ was the result of subclinical cardiac dysfunction present on enrolment. The association of low DBP, but not PP, with incident VHF, together with NT-proBNP level, may reflect, in part, unrecognised valvular dysfunction on enrolment. 
Cardiac risk factors and prevention

Table 3 Cox regression: multivariable subdistribution HRs

\begin{tabular}{|c|c|c|c|c|c|c|c|c|}
\hline & $\begin{array}{l}\text { Total HF } \\
\text { HR (95\% Cl) }\end{array}$ & $P$ values & $\begin{array}{l}\text { HFpEF } \\
\text { HR (95\% CI) }\end{array}$ & P values & $\begin{array}{l}\text { HFrEF } \\
\text { HR }(95 \% \mathrm{CI})\end{array}$ & $P$ values & $\begin{array}{l}\text { VHF } \\
\text { HR (95\% Cl) }\end{array}$ & $P$ values \\
\hline Age (per decade) & $\begin{array}{l}1.9 \\
(1.5 \text { to } 2.4)\end{array}$ & $<0.0001$ & $\begin{array}{l}2.3 \\
\text { (1.6 to } 3.3 \text { ) }\end{array}$ & $<0.0001$ & $\begin{array}{l}1.6 \\
\text { (1.1 to } 2.5 \text { ) }\end{array}$ & 0.019 & & \\
\hline Male gender & & & & & $\begin{array}{l}3.1 \\
(1.6 \text { to } 6.0)\end{array}$ & 0.0011 & & \\
\hline $\begin{array}{l}\text { DBP } \\
\text { (per } 10 \mathrm{~mm} \mathrm{Hg} \text { ) }\end{array}$ & & & & & & & $\begin{array}{l}0.7 \\
(0.5 \text { to } 0.9)\end{array}$ & 0.012 \\
\hline $\begin{array}{l}\text { Log BMI (per } \\
\text { doubling) }\end{array}$ & $\begin{array}{l}5.7 \\
\text { (3.1 to 10.5) }\end{array}$ & $<0.0001$ & $\begin{array}{l}25 \\
(11 \text { to } 58)\end{array}$ & $<0.0001$ & & & & \\
\hline $\begin{array}{l}\text { Waist } \\
\text { circumference } \\
\text { (per } 10 \mathrm{~cm})\end{array}$ & & & & & $\begin{array}{l}1.29 \\
(1.02 \text { to } 1.62)\end{array}$ & 0.035 & & \\
\hline Hypertension & & & $\begin{array}{l}3.5 \\
(1.4 \text { to } 8.8)\end{array}$ & 0.0068 & & & & \\
\hline Diabetes & $\begin{array}{l}1.7 \\
(1.2 \text { to } 2.3)\end{array}$ & 0.0046 & $\begin{array}{l}3.1 \\
(1.9 \text { to } 5.0)\end{array}$ & $<0.0001$ & & & & \\
\hline $\begin{array}{l}\text { Myocardial } \\
\text { infarction }\end{array}$ & $\begin{array}{l}1.6 \\
(1.1 \text { to } 2.3)\end{array}$ & 0.0083 & $\begin{array}{l}2.3 \\
(1.4 \text { to } 3.8)\end{array}$ & 0.0019 & $\begin{array}{l}1.9 \\
(1.1 \text { to } 3.4)\end{array}$ & 0.029 & & \\
\hline AF & & & $\begin{array}{l}3.3 \\
(1.9 \text { to } 5.7)\end{array}$ & $<0.0001$ & & & & \\
\hline OSA & $\begin{array}{l}1.7 \\
(1.1 \text { to } 2.7)\end{array}$ & 0.026 & & & & & & \\
\hline $\begin{array}{l}\text { Current or former } \\
\text { smoker }\end{array}$ & $\begin{array}{l}1.42 \\
\text { (1.04 to } 1.94)\end{array}$ & 0.027 & & & & & & \\
\hline $\begin{array}{l}\text { Alcohol>2 drinks/ } \\
\text { day }^{\star}\end{array}$ & & & & & & & $\begin{array}{l}2.7 \\
(1.4 \text { to } 5.4)\end{array}$ & 0.0047 \\
\hline $\begin{array}{l}\text { NT-proBNP } \\
\text { quintile }\end{array}$ & $\begin{array}{l}2.0 \\
(1.7 \text { to } 2.3)\end{array}$ & $<0.0001$ & $\begin{array}{l}1.8 \\
(1.4 \text { to } 2.3)\end{array}$ & $<0.0001$ & $\begin{array}{l}2.0 \\
(1.5 \text { to } 2.6)\end{array}$ & $<0.0001$ & $\begin{array}{l}1.8 \\
(1.3 \text { to } 2.4)\end{array}$ & 0.0003 \\
\hline $\begin{array}{l}\text { Haemoglobin } \\
(\mathrm{g} / \mathrm{dL})\end{array}$ & & & $\begin{array}{l}0.81 \\
(0.68 \text { to } 0.97)\end{array}$ & 0.023 & & & & \\
\hline ССВ & & & $\begin{array}{l}0.56 \\
(0.33 \text { to } 0.95)\end{array}$ & 0.031 & & & & \\
\hline C statistics† & $\begin{array}{l}0.80 \\
(0.78 \text { to } 0.81)\end{array}$ & & $\begin{array}{l}0.78 \\
(0.50 \text { to } 0.85)\end{array}$ & & $\begin{array}{l}0.73 \\
(0.66 \text { to } 0.79)\end{array}$ & & $\begin{array}{l}0.76 \\
(0.72 \text { to } 0.79)\end{array}$ & \\
\hline
\end{tabular}

Multivariable HRs and 95\% Cls for risk factors for total incident HF, HFpEF, HFrEF and VHF.

HRs were calculated using a semiparametric proportional hazards model for the subdistribution of competing risk. ${ }^{14}$

Median (IQR) determined by the bootstrap method.

${ }^{*}$ Refers to consumption of more than two standard drinks on any day.

†C statistics for each multivariable model were estimated for a follow-up of 5.5 years.

$\mathrm{AF}$, atrial fibrillation; BMI, body mass index; CCB, calcium channel blocker; DBP, diastolic blood pressure; HF, heart failure; HFpEF, heart failure with preserved ejection fraction; HFrEF, heart failure with reduced ejection fraction; NT-proBNP, amino-terminal pro-B-type natriuretic peptide; OSA, obstructive sleep apnoea; VHF, valvular heart failure; WCC, white cell count.

A key finding of our study was the number of risk factors that suggest a major role for increased BMI in the pathogenesis of HFpEF. The contribution of increased BMI to type 2 diabetes and hypertension is well recognised. Obesity is not associated with lower haemoglobin levels in the general population, ${ }^{23}$ and therefore does not explain the association of HFpEF with lower haemoglobin levels. However, the association of NT-proBNP levels and reduced eGFR with incident HFpEF in our study suggests that either or both subclinical cardiac dysfunction and fluid retention may have contributed to increased plasma volume, and thereby reduced haemoglobin levels by haemodilution in these SCREEN-HF participants, ${ }^{24} \mathrm{a}$ possibility that is consistent with the association of loop diuretic therapy with incident HFpEF. The association of increased WCC with incident HFpEF is consistent with a chronic inflammatory state that may be a consequence of increased adipose tissue mass, ${ }^{25}$ and such a chronic inflammatory state may have contributed to lower haemoglobin levels. The association of $\beta$-blocker, statin and clopidogrel therapies with incident HFpEF may reflect the association of these therapies with underlying 
vascular disease, whereas the association of NSAIDs with incident HFpEF is in agreement with the doubling of $\mathrm{HF}$ risk by these drugs. ${ }^{26}$

Our findings provide support for the existence of a distinct obese phenotype of HFpEF. ${ }^{24}$ Increased BMI preceded HFpEF diagnosis by a median of 4-5 years in the SCREEN-HF cohort, providing opportunity for intervention and possible prevention of HFpEF. The many mechanisms that may contribute to the impaired diastolic filling that characterises obesity include reduced coronary microvascular density consequent to cardiomyocyte hypertrophy. ${ }^{27}$ Although we currently have no therapies that improve prognosis in HFpEF, several strategies have been shown to improve diastolic function and may therefore prevent or postpone HFpEF. Blood pressure-lowering therapies prevent $\mathrm{HF}^{28-30}$ and it is likely that this is due in part to prevention of HFpEF by reducing myocardial fibrosis and LV mass, and improving diastolic function. ${ }^{31-34}$ Moreover, weight reduction in obesity reduces LV mass and improves diastolic function, ${ }^{35-37}$ vigorous physical activity is associated with reduced HF incidence independently of $\mathrm{BMI}^{38}$ and caloric restriction improves diastolic function in individuals who are not obese with evidence of diastolic dysfunction and ameliorates age-associated decline in diastolic function. ${ }^{39} 40$

\section{Strengths and limitations}

The strengths of our study include the diagnosis of HF in a predominantly ambulant setting, the long duration of observation such that risk factor information was collected well before HF diagnosis, the separation of VHF from HFpEF and HFrEF and the identification of many risk factors for incident HFpEF. However, the large number of baseline variables tested for association with HF development was accompanied by the potential for type 1 error and false discovery of associations, and each risk factor we identified is hypothesis generating with respect to pathophysiological mechanisms. In addition, the modest number of participants who developed HF makes our findings susceptible to type 2 error, in that we cannot exclude any risk factor as a contributor to the pathogenesis of any of the categories of HF. Our selection criteria likely biased the risk factors for HF; for example, the high prevalence of hypertension would have reduced the ability of this well-recognised HF risk factor to discriminate between participants. Moreover, our reliance on qualitative estimates of LVEF for a proportion of participants diagnosed with HFrEF prevented their subclassification as mid-range or more severe HFrEF. Furthermore, despite our attempts to capture all incident cases of HF we may have missed some cases of early HF, and we may have also missed cases because we were reliant on phone review to pick up HF in approximately 500 participants. The inclusion criteria with respect to age and cardiovascular risk factors, together with the SCREEN-HF cohort comprising volunteers who were predominantly members of a health fund, prevent generalisation of our incidence data to the general community. However, our inclusion criteria would have captured up to $90 \%$ of individuals in the general community at risk of $\mathrm{HF}^{41}$ and thus our risk factor data are applicable to the general community. Although baseline imaging data were incomplete and we may have enrolled participants with unrecognised LV dysfunction, including valvular dysfunction, the long delay in HF onset suggests that any LV dysfunction on enrolment was minor and likely to be subclinical. The echocardiographic examinations performed as part of the SCREEN-HF study will be the subject of future analyses.

\section{CONCLUSIONS}

We identified risk factors for incident HFpEF, HFrEF and VHF that preceded HF development by many years, and suggest that the mechanisms of HF pathogenesis were operating many years before HF diagnosis. Each risk factor we identified is hypothesis generating with respect to pathophysiological mechanisms of HF and potential therapeutic approaches. In particular, our data suggest a major role for BMI, hypertension, diabetes, renal dysfunction and inflammation in HFpEF pathogenesis. Strategies directed to prevention of these HFpEF risk factors may prevent a sizeable proportion of HFpEF in the community.

\section{Author affiliations}

${ }^{1}$ St. Vincent's Institute of Medical Research, Melbourne, Victoria, Australia ${ }^{2}$ University of Melbourne, Melbourne, Victoria, Australia

${ }^{3}$ St. Vincent's Hospital, Melbourne, Victoria, Australia

${ }^{4}$ Royal Prince Alfred Hospital, Camperdown, New South Wales, Australia

${ }^{5}$ School of Public Health and Preventive Medicine, Monash University, Melbourne, Victoria, Australia

${ }^{6}$ Mary MacKillop Institute for Health Research, Australian Catholic University, Melbourne, Victoria, Australia

${ }^{7}$ School of Public Health, Curtin University, Bentley, Western Australia, Australia

Acknowledgements The authors are very grateful to Bupa Australia and to Sonia Danielewski for their contribution to study recruitment, and to Dorevitch Pathology. The authors would like to thank all SCREEN-HF study participants and the study nurses, echocardiographers and administrative staff for their invaluable contribution.

Contributors FFG: data collection, data analysis, initial drafting, critical review and final revision. MVJ, JMCa, JMCo, MM: data collection, data analysis, critical review and final revision. UB, LS, DL, RW, SS, HK, CMR: study design, data analysis, critical review and final revision. AJO: data analysis, critical review and final revision. DLP, DJC: study design, data collection, data analysis, critical review and final revision. All authors reviewed and approved the final draft of this manuscript. They take full responsibility for all parts of this paper.

Funding The SCREEN-HF study was initially funded by Bupa Australia, with subsequent support from the National Health and Medical Research Council (NHMRC) of Australia, the National Heart Foundation of Australia and the Diabetes Australia Research Trust. DJC and SS received senior research fellowships from the NHMRC, and MM and JMCo received scholarship support from the NHMRC. St Vincent's Institute of Medical Research is supported in part by the Victorian Government's Operational Infrastructure Support Program.

Disclaimer Bupa Australia was involved in study design, recruitment of participants and funding, but was not involved in data collection, analysis or interpretation, or writing of the article. Bupa Australia had no control or influence over the decision to submit the final manuscript for publication.

Competing interests DJC has received payments from the Australasian Renin Academy for lectures. JMCa has received payments from Pfizer, Servier, Bayer and Alphpharm for lectures. DLP has received payment from Servier for sitting on their 
advisory board, and from Boehringer Ingelheim, CSL, Merck Sharp \& Dohme and Sanofi Aventis for lectures. UB was an employee of Bupa Australia. DL has received honoraria from Pfizer, Sanofi, Astra-Zeneca, Abbott, Bayer, MSD, GSK, Novartis and Nycomed. SS has received unrestricted educational grants from Schering Plough and Boehringer Ingelheim, and was Principal Investigator of the Novartis sponsored Valsartan Intensified Primary Care Reduction of Blood Pressure (VIPER-BP) Study. HK received support from Novartis, Bristol-Myers Squibb and Ardian/Medtronic. Patient consent Not required.

Ethics approval Alfred Human Research Ethics Committee.

Provenance and peer review Not commissioned; externally peer reviewed.

Open access This is an open access article distributed in accordance with the Creative Commons Attribution Non Commercial (CC BY-NC 4.0) license, which permits others to distribute, remix, adapt, build upon this work non-commercially, and license their derivative works on different terms, provided the original work is properly cited, appropriate credit is given, any changes made indicated, and the use is non-commercial. See:http://creativecommons.org/licenses/by-nc/4.0/

\section{REFERENCES}

1. Huffman MD, Berry JD, Ning $\mathrm{H}$, et al. Lifetime risk for heart failure among white and black Americans: cardiovascular lifetime risk pooling project. J Am Coll Cardiol 2013;61:1510-7.

2. Yancy CW, Jessup $M$, Bozkurt $B$, et al. ACCF/AHA guideline for the management of heart failure: a report of the American College of Cardiology Foundation/American Heart Association Task Force on Practice Guidelines. J Am Coll Cardiol 2013;2013:e147-e239.

3. McMurray JJ, Adamopoulos S, Anker SD, et al. ESC Guidelines for the diagnosis and treatment of acute and chronic heart failure 2012: The Task Force for the Diagnosis and Treatment of Acute and Chronic Heart Failure 2012 of the European Society of Cardiology. Developed in collaboration with the Heart Failure Association (HFA) of the ESC. Eur Heart J 2012;33:1787-847.

4. Ponikowski P, Voors AA, Anker SD, et al. ESC Guidelines for the diagnosis and treatment of acute and chronic heart failure: The Task Force for the diagnosis and treatment of acute and chronic heart failure of the European Society of Cardiology (ESC) Developed with the special contribution of the Heart Failure Association (HFA) of the ESC. Eur Heart J 2016;2016:2129-200.

5. Dunlay SM, Roger VL, Redfield MM. Epidemiology of heart failure with preserved ejection fraction. Nat Rev Cardiol 2017:14:591-602.

6. Aurigemma GP, Gottdiener JS, Shemanski L, et al. Predictive value of systolic and diastolic function for incident congestive heart failure in the elderly: the cardiovascular health study. J Am Coll Cardiol 2001;37:1042-8.

7. Lee DS, Gona P, Vasan RS, et al. Relation of disease pathogenesis and risk factors to heart failure with preserved or reduced ejection fraction: insights from the framingham heart study of the national heart, lung, and blood institute. Circulation 2009;119:3070-7.

8. Ho JE, Lyass A, Lee DS, et al. Predictors of new-onset heart failure: differences in preserved versus reduced ejection fraction. Circ Heart Fail 2013;6:279-86.

9. Brouwers FP, de Boer RA, van der Harst P, et al. Incidence and epidemiology of new onset heart failure with preserved vs. reduced ejection fraction in a community-based cohort: 11-year follow-up of PREVEND. Eur Heart J 2013;34:1424-31.

10. Ho JE, Enserro D, Brouwers FP, et al. Predicting heart failure with preserved and reduced ejection fraction: the international collaboration on heart failure subtypes. Circ Heart Fail 2016;9:e003116.

11. Senni M, Tribouilloy CM, Rodeheffer RJ, et al. Congestive heart failure in the community: a study of all incident cases in Olmsted County, Minnesota, in 1991. Circulation 1998;98:2282-9.

12. Campbell DJ, Coller JM, Gong FF, et al. Risk factor management in a contemporary Australian population at increased cardiovascular disease risk. Intern Med J. 201848688 698.]

13. Levey AS, Bosch JP, Lewis JB, et al. A more accurate method to estimate glomerular filtration rate from serum creatinine: a new prediction equation. Modification of Diet in Renal Disease Study Group. Ann Intern Med 1999:130:461-70.

14. Fine JP, Gray RJ. A proportional hazards model for the subdistribution of a competing risk. J Am Stat Assoc 1999;94:496-509.

15. Lunn M, McNeil D. Applying Cox regression to competing risks. Biometrics 1995:51:524-32.
16. Blanche P, Dartigues JF, Jacqmin-Gadda H. Estimating and comparing time-dependent areas under receiver operating characteristic curves for censored event times with competing risks. Stat Med 2013;32:5381-97.

17. Braunwald E. Heart failure. JACC Heart Fail 2013;1:1-20.

18. Yang $\mathrm{H}$, Negishi K, Otahal $\mathrm{P}$, et al. Clinical prediction of incident heart failure risk: a systematic review and meta-analysis. Open Heart 2015;2:e000222.

19. Chae CU, Pfeffer MA, Glynn RJ, et al. Increased pulse pressure and risk of heart failure in the elderly. JAMA 1999;281:634-9.

20. Goldbarg SH, Elmariah S, Miller MA, et al. Insights into degenerative aortic valve disease. J Am Coll Cardiol 2007;50:1205-13.

21. Delling FN, Vasan RS. Epidemiology and pathophysiology of mitral valve prolapse: new insights into disease progression, genetics, and molecular basis. Circulation 2014;129:2158-70.

22. Kass DA. Age-related changes in venticular-arterial coupling: pathophysiologic implications. Heart Fail Rev 2002;7:51-62.

23. Ausk KJ, loannou GN. Is obesity associated with anemia of chronic disease? A population-based study. Obesity 2008;16:2356-61.

24. Obokata M, Reddy YNV, Pislaru SV, et al. Evidence supporting the existence of a distinct obese phenotype of heart failure with preserved ejection fraction. Circulation 2017;136:6-19.

25. Hajer GR, van Haeften TW, Visseren FL. Adipose tissue dysfunction in obesity, diabetes, and vascular diseases. Eur Heart $J$ 2008;29:2959-71.

26. Bhala N, Emberson J, Merhi A, et al. Vascular and upper gastrointestinal effects of non-steroidal anti-inflammatory drugs: meta-analyses of individual participant data from randomised trials. Lancet 2013;382:769-79.

27. Campbell DJ, Somaratne JB, Prior DL, et al. Obesity is associated with lower coronary microvascular density. PLoS One 2013;8:e81798.

28. Dagenais GR, Pogue J, Fox K, et al. Angiotensin-converting-enzyme inhibitors in stable vascular disease without left ventricular systolic dysfunction or heart failure: a combined analysis of three trials. Lancet 2006;368:581-8.

29. Ettehad D, Emdin CA, Kiran A, et al. Blood pressure lowering for prevention of cardiovascular disease and death: a systematic review and meta-analysis. Lancet 2016;387:957-67.

30. Sundstrom J, Arima H. Blood Pressure Lowering Treatment Trialists' Collaboration. Blood pressure-lowering treatment based on cardiovascular risk: a meta-analysis of individual patient data. Lancet 2014;384:591-8

31. Devereux RB, Wachtell K, Gerdts E, et al. Prognostic significance of left ventricular mass change during treatment of hypertension. JAMA 2004;292:2350-6.

32. Solomon SD, Janardhanan R, Verma A, et al. Effect of angiotensin receptor blockade and antihypertensive drugs on diastolic function in patients with hypertension and diastolic dysfunction: a randomised trial. Lancet 2007;369:2079-87.

33. Wachtell K, Bella JN, Rokkedal J, et al. Change in diastolic left ventricular filling after one year of antihypertensive treatment: The Losartan Intervention For Endpoint Reduction in Hypertension (LIFE) Study. Circulation 2002;105:1071-6.

34. Brilla CG, Funck RC, Rupp H. Lisinopril-mediated regression of myocardial fibrosis in patients with hypertensive heart disease. Circulation 2000;102:1388-93.

35. Tuluce K, Kara C, Tuluce SY, et al. Early reverse cardiac remodeling effect of laparoscopic sleeve gastrectomy. Obes Surg 2017;27:364-75

36. Shin SH, Lee YJ, Heo YS, et al. Beneficial effects of bariatric surgery on cardiac structure and function in obesity. Obes Surg 2017;27:620-5

37. Karimian S, Stein J, Bauer B, et al. Improvement of impaired diastolic left ventricular function after diet-induced weight reduction in severe obesity. Diabetes Metab Syndr Obes 2017;10:19-25.

38. Kenchaiah S, Sesso HD, Gaziano JM. Body mass index and vigorous physical activity and the risk of heart failure among men. Circulation 2009;119:44-52.

39. Riordan MM, Weiss EP, Meyer TE, et al. The effects of caloric restriction- and exercise-induced weight loss on left ventricular diastolic function. Am J Physiol Heart Circ Physiol 2008;294:H117 4-H1182.

40. Meyer TE, Kovács SJ, Ehsani AA, et al. Long-term caloric restriction ameliorates the decline in diastolic function in humans. J Am Coll Cardiol 2006;47:398-402.

41. Wilhelmsen L, Rosengren A, Eriksson $\mathrm{H}$, et al. Heart failure in the general population of men--morbidity, risk factors and prognosis. $J$ Intern Med 2001;249:253-61. 
Correction: Risk factors for incident heart failure with

preserved or reduced ejection fraction, and valvular heart

failure, in a community-based cohort

Gong FF, Jelinek MV, Castro JM, et al. Risk factors for incident heart failure with preserved or reduced ejection fraction, and valvular heart failure, in a communitybased cohort. Open Heart 2018;5:e000782. doi: 10.1136/openheart-2018-000782

The authors want to alert readers to an error identified in reference (12) in the published version. The correct version is now stated below:

Campbell DJ, Coller JM, Gong FF, et al. Risk factor management in a contemporary Australian population at increased cardiovascular disease risk. Intern Med J 2018;48:688-98.

Open access This is an open access article distributed in accordance with the Creative Commons Attribution Non Commercial (CC BY-NC 4.0) license, which permits others to distribute, remix, adapt, build upon this work non-commercially, and license their derivative works on different terms, provided the original work is properly cited, appropriate credit is given, any changes made indicated, and the use is non-commercial. See: http://creativecommons.org/licenses/by-nc/4.0/

Open Heart 2018;5. doi:10.1136/openhrt-2018-000782corr1

A) Check for updates 